\title{
An exploration of ozone changes and their radiative forcing prior to the chlorofluorocarbon era
}

\author{
D. T. Shindell ${ }^{1,2}$ and G. Faluvegi ${ }^{1,2}$ \\ ${ }^{1}$ NASA Goddard Institute for Space Studies, New York, New York, USA \\ ${ }^{2}$ also at: Center for Climate Systems Research, Columbia University, New York, USA
}

Received: 2 August 2002 - Published in Atmos. Chem. Phys. Discuss.: 18 September 2002

Revised: 14 November 2002 - Accepted: 18 November 2002 - Published: 28 November 2002

\begin{abstract}
Using historical observations and model simulations, we investigate ozone trends prior to the mid-1970s onset of halogen-induced ozone depletion. Though measurements are quite limited, an analysis based on multiple, independent data sets (direct and indirect) provides better constraints than any individual set of observations. We find that three data sets support an apparent long-term stratospheric ozone trend of $-7.2 \pm 2.3$ DU during 1957-1975, which modeling attributes primarily to water vapor increases. The results suggest that 20th century stratospheric ozone depletion may have been roughly $50 \%$ more than is generally supposed. Similarly, three data sets support tropospheric ozone increases over polluted Northern Hemisphere continental regions of $8.2 \pm 2.1 \mathrm{DU}$ during this period, which are mutually consistent with the stratospheric trends. As with paleoclimate data, which is also based on indirect proxies and/or limited spatial coverage, these results must be interpreted with caution. However, they provide the most thorough estimates presently available of ozone changes prior to the coincident onset of satellite data and halogen dominated ozone changes. If these apparent trends were real, the radiative forcing by stratospheric ozone since the 1950s would then have been $-0.15 \pm 0.05 \mathrm{~W} / \mathrm{m}^{2}$, and $-0.2 \mathrm{~W} / \mathrm{m}^{2}$ since the preindustrial. For tropospheric ozone, it would have been $0.38 \pm 0.10 \mathrm{~W} / \mathrm{m}^{2}$ since the late 1950s. Combined with even a very conservative estimate of tropospheric ozone forcing prior to that time, this would be larger than current estimates since 1850 which are derived from models that are even less well constrained. These calculations demonstrate the importance of gaining a better understanding of historical ozone changes.
\end{abstract}

Correspondence to: D. T. Shindell

(dshindell@giss.nasa.gov)

\section{Introduction}

Greenhouse gases (GHGs) can be divided into two types: long-lived, relatively stable gases, and short-lived, reactive gases. Trends in the long-lived gases, $\mathrm{CO}_{2}, \mathrm{CH}_{4}, \mathrm{~N}_{2} \mathrm{O}$, and chlorofluorocarbons (CFCs), have been measured since the 1950s, and data previous to that time are available from ice cores. Since these gases are well-mixed in the atmosphere, surface data from a single location are in principle adequate to determine their global distributions. Both their modern and historical behavior is therefore well known, and their radiative forcing is regarded as known with "very high" confidence (Intergovernmental Panel on Climate Change, 2001; hereafter IPCC, 2001). For the short-lived greenhouse gases ozone and water vapor, however, little is known about their historical trends. Ozone is too reactive to leave useful traces in ice cores, while the hydrological cycle thoroughly obscures records of past water vapor concentrations. We are therefore restricted to direct measurements, which are almost exclusively from the late twentieth century. Furthermore, since the distribution of these two gases is very inhomogeneous in the troposphere, data from many locations and at many altitudes are necessary to give an adequate picture of their global abundances. Trends in the tropospheric abundance of both of these gases are therefore poorly known, as data are sparse. In the stratosphere, these gases are both distributed more homogeneously, and more data are available. For ozone, reliable global stratospheric data became available in 1979, and trends can be accurately estimated since that time (Harris et al., 1997; World Meteorological Organization, 1999; hereafter WMO, 1999; Staehelin et al., 2001) (Limited satellite data are available from the BUV instrument for 1970-1977, but have numerous drift problems; Rodgers, 1988; Heath, 1988). Yet that time coincides with the onset of ozone depletion induced by halogens released from CFCs. Ozone trends during the 1980s and 1990s would therefore 
not be expected to be representative of ozone's behavior during earlier times, which remains poorly known. For stratospheric water vapor, though the data are limited in coverage to northern mid-latitudes, trends have very recently been extended back before the mid-1970s (Oltmans et al., 2000; Rosenlof et al., 2001), and the satellite data suggest that northern mid-latitudes are in fact globally representative.

Large scale tropospheric and total column ozone trends prior to the late 1970s onset of the chlorofluorocarbon and satellite eras were investigated in the past (Komhyr et al., 1971; Johnston et al., 1973; London and Kelley, 1974; Parry, 1977; Angell and Korshover, 1978; Logan, 1985). Recent studies, however, have tended not to analyze this unique period, concentrating on more recent times (Krzyscin, 1994; Harris et al., 1997; WMO, 1999; Staehelin et al., 2001). Though column data from Arosa prior to the mid-1970s are often discussed, a single location is inadequate to determine large-scale trends. Given the importance of historical ozone trends for climate, and the emergence of new data sets, we believe it is an appropriate time to revisit this topic in an exploratory manner.

While the available data prior to the mid-1970s are quite limited in spatial and temporal coverage, they nevertheless provide the only means to constrain the historical behavior of ozone and water vapor prior to the onset of halogen-induced ozone depletion. We combine existing data, including the recent analyses of water vapor trends, with a new analysis of column ozone data presented here, to obtain a more complete multisource record of historical trends. While the limitations of the data are significant, trends in ozone and water vapor are coupled, so that there are fewer degrees of freedom when the system as a whole is studied. In fact, the system is overconstrained, so that each trend is forced by at least two data sets. Thus the conclusions are relatively robust even if one of the data sets does not accurately represent past trends. Taken in its entirety, we therefore believe that the data, including the new analyses of water and column ozone, are now sufficient to allow a meaningful attempt to develop a coherent, selfconsistent scenario for trends in the reactive climate gases (except for tropospheric water vapor). We emphasize that similar to paleoclimate data, which are widely used to investigate climate prior to thermometer measurements, these data must be interpreted with caution, but we feel that both types of data are nevertheless valuable for providing at least limited information on an otherwise unknown period of the past. While the data cover only the period from the late 1950 s to the late 1970 s, the trends indicate the ozone and water response to long-term increases in emissions of $\mathrm{CO}_{2}$, $\mathrm{N}_{2} \mathrm{O}, \mathrm{CH}_{4}$, and ozone precursors. These were the main factors driving changes throughout the industrial era (prior to the 1970s increases in CFCs), and have largely increased monotonically. The 1950s to 1970 s trends may therefore be extrapolated back throughout the industrial era with some degree of confidence (especially in the stratosphere). We present 2sigma uncertainties throughout this paper, as we feel these connote a more realistic range given the limited data available and the inferences required for indirect measurements. We focus initially on the period from 1957-1975.

\section{The five data sets}

Five independent data sets provide valuable constraints, primarily at mid-latitudes, and we describe each briefly in turn. Observations show a positive water vapor trend in the stratosphere. An analysis of ten different data sets covering the years $1954-2000$ yields an overall increase of $1 \% \mathrm{yr}^{-1}$, or about 0.4 to 0.5 ppmv per decade in the lower stratosphere (Rosenlof et al., 2001). This trend is based on data at Northern Hemisphere (NH) mid-latitudes taken by ground-based, balloon-borne, aircraft, satellite and Space Shuttle borne instruments. Though early data coverage are very sparse, the fact that ten data sets taken by five types of instruments show similar trends gives us a reasonable degree of confidence in this value.

Total column ozone measurements at many stations date from the International Geophysical Year in 1957. Several trend analyses have been performed on these data covering the period since the 1970s (Bojkov et al., 1995; WMO, 1995; Harris et al., 1997; WMO, 1999). Ozone depletion since then, however, has been predominantly due to the large increases in halogens since the mid-1970s, driven by the production of CFCs. We have therefore performed our own analysis to derive trends over the period from 1957-1975. Although the data are somewhat less reliable for this period, there are still a large number of stations, and it provides the best indication of stratospheric ozone's response to long-term changes prior to anthropogenic halogens. We used column ozone values obtained from the World Ozone Data Center in Toronto. The data were carefully screened to produce the most reliable trend estimates, and closely examined for systematic biases in order to compensate for the poor quality of some of the data in the archive (see Appendix). Unfortunately, few stations are available for the Southern Hemisphere ( $\mathrm{SH})$, though coverage is more thorough in the Northern Hemisphere (NH). Station data used in calculating the trends are summarized in Table 1. Best estimate mid-latitude column trends are $3.5 \pm 2.2 \mathrm{DU}$ for the $\mathrm{NH}$, and $-9.6 \pm 6.6$ DU for the SH. The values for the $\mathrm{NH}$ are smaller than those found in studies performed during the 1970s. Those found trends of approximately $16 \pm 4$ DU for 1960-1970 using 76 stations between 0 and $90 \mathrm{~N}$ (Johnston et al., 1973), about $30 \pm 9$ DU for 1957-1970 using around $80 \mathrm{NH}$ stations, or about 9-12 DU from the early 1960s to the mid-1970s using around 50 stations at Northern mid-latitudes (Parry, 1977; Angell and Korshover, 1978). We believe that these trends are too large, and that our screening process, corrections for aerosols and discontinuities, and exclusion of the polar regions (see Appendix) provide more reliable estimates than the earlier calculations. A similar conclusion was in fact im- 
Table 1. Observed 1957-1975 ozone column trends (DU) for stations meeting "best estimate" criteria

\begin{tabular}{|c|c|c|c|c|c|c|c|}
\hline Location & Latitude & Longitude & Trend & 1 -sigma & $\begin{array}{c}\text { Years } \\
\text { of data }\end{array}$ & $\begin{array}{c}\text { Instrument } \\
\text { Code }\end{array}$ & $\begin{array}{r}\text { Altitude } \\
\text { (m) }\end{array}$ \\
\hline Edmonton & $53.5 \mathrm{~N}$ & $114.1 \mathrm{~W}$ & 16.4 & 6.4 & 19 & 03 & 766 \\
\hline Goose Bay & $53.3 \mathrm{~N}$ & $60.3 \mathrm{~W}$ & 22.9 & 8.6 & 14 & 03 & 44 \\
\hline Potsdam & $52.2 \mathrm{~N}$ & $13.1 \mathrm{E}$ & 1.8 & 14.8 & 12 & 03 & 89 \\
\hline Belsk & $51.8 \mathrm{~N}$ & $20.8 \mathrm{E}$ & -4.0 & 11.2 & 13 & 03 & 180 \\
\hline Oxford & $51.8 \mathrm{~N}$ & $1.2 \mathrm{~W}$ & 19.0 & 5.1 & 19 & 03 & 140 \\
\hline Bracknell & $51.4 \mathrm{~N}$ & $0.8 \mathrm{~W}$ & -14.9 & 12.7 & 9 & 03 & 70 \\
\hline Uccle & $50.8 \mathrm{~N}$ & $4.3 \mathrm{E}$ & 14.8 & 13.8 & 10 & 03 & 100 \\
\hline Hradec Kralove & $50.2 \mathrm{~N}$ & $15.8 \mathrm{E}$ & 11.9 & 11.6 & 15 & 03 & 285 \\
\hline Caribou & $46.9 \mathrm{~N}$ & $68.0 \mathrm{~W}$ & 10.9 & 7.4 & 16 & 03 & 192 \\
\hline Arosa & $46.8 \mathrm{~N}$ & $9.7 \mathrm{E}$ & 0.5 & 5.2 & 19 & 03 & 1840 \\
\hline Bismarck & $46.8 \mathrm{~N}$ & $100.8 \mathrm{~W}$ & 11.4 & 5.1 & 17 & 03 & 511 \\
\hline Green Bay & $44.5 \mathrm{~N}$ & $88.1 \mathrm{~W}$ & 10.4 & 9.4 & 15 & 03 & 209 \\
\hline Toronto & $43.8 \mathrm{~N}$ & $79.5 \mathrm{~W}$ & 6.6 & 6.7 & 16 & 03 & 198 \\
\hline Cagliari & $43.3 \mathrm{~N}$ & $42.5 \mathrm{E}$ & 27.3 & 8.6 & 19 & 03 & 2100 \\
\hline Sapporo & $43.0 \mathrm{~N}$ & $141.3 \mathrm{E}$ & -22.4 & 5.7 & 18 & 04 & 19 \\
\hline Mont Louis & $42.5 \mathrm{~N}$ & $2.1 \mathrm{E}$ & 30.5 & 7.9 & 14 & 03 & 1650 \\
\hline Bedford & $42.5 \mathrm{~N}$ & $71.3 \mathrm{~W}$ & 29.5 & 13.8 & 9 & 03 & 80 \\
\hline Vigna di Valle & $42.1 \mathrm{~N}$ & $12.2 \mathrm{E}$ & 5.7 & 5.0 & 19 & 03 & 262 \\
\hline Naples & $40.8 \mathrm{~N}$ & $15.2 \mathrm{E}$ & -9.3 & 8.2 & 13 & 03 & 45 \\
\hline Boulder & $40.0 \mathrm{~N}$ & $105.2 \mathrm{~W}$ & -8.4 & 8.8 & 12 & 03 & 1689 \\
\hline Messina & $38.2 \mathrm{~N}$ & $15.6 \mathrm{E}$ & -2.4 & 7.2 & 19 & 03 & 51 \\
\hline Nashville & $36.2 \mathrm{~N}$ & $86.6 \mathrm{~W}$ & 10.5 & 8.5 & 14 & 03 & 182 \\
\hline Tateno & $36.0 \mathrm{~N}$ & $140.1 \mathrm{E}$ & -9.5 & 3.3 & 19 & 03 & 31 \\
\hline Srinagar & $34.1 \mathrm{~N}$ & $74.8 \mathrm{E}$ & -14.6 & 4.5 & 17 & 03 & 1586 \\
\hline Kagoshima & $31.5 \mathrm{~N}$ & $130.6 \mathrm{E}$ & 2.9 & 3.0 & 16 & 04 & 31 \\
\hline Tallahassee & $30.4 \mathrm{~N}$ & $84.3 \mathrm{~W}$ & 13.5 & 8.8 & 10 & 03 & 21 \\
\hline Quetta & $30.1 \mathrm{~N}$ & $66.6 \mathrm{E}$ & -1.3 & 5.4 & 16 & 03 & 1721 \\
\hline Varanasi & $25.3 \mathrm{~N}$ & $83.0 \mathrm{E}$ & 23.8 & 9.1 & 13 & 03 & 76 \\
\hline Mount Abu & $24.6 \mathrm{~N}$ & $72.7 \mathrm{E}$ & 13.2 & 5.2 & 11 & 03 & 1220 \\
\hline Ahmedabad & $23.0 \mathrm{~N}$ & $72.7 \mathrm{E}$ & 8.0 & 7.0 & 10 & 03 & 55 \\
\hline Dum Dum & $22.6 \mathrm{~N}$ & $88.4 \mathrm{E}$ & 13.1 & 8.9 & 11 & 03 & 27 \\
\hline Pretoria & $25.7 \mathrm{~S}$ & $28.2 \mathrm{E}$ & -28.1 & 12.1 & 9 & 03 & 1369 \\
\hline Brisbane & $27.4 \mathrm{~S}$ & $153.1 \mathrm{E}$ & -5.4 & 5.1 & 19 & 03 & 3 \\
\hline Aspendale & $38.0 \mathrm{~S}$ & $145.1 \mathrm{E}$ & -10.9 & 4.9 & 19 & 03 & 1 \\
\hline Macquarie Is. & $54.5 \mathrm{~S}$ & $159.0 \mathrm{E}$ & -3.7 & 15.9 & 10 & 03 & 6 \\
\hline
\end{tabular}

plicitly reached by Johnston et al. (1973), who showed that when screened to include only the stations with at least 30 months of observations during 1960-1962 and 1963-1970 ( 30 out of 76 in the $\mathrm{NH}, 2$ out of 17 in the $\mathrm{SH}$ ), their trends became about 7.5 DU for 1960-1970 in the NH, and -6.7 DU in the SH. Stratospheric trends were probably similar in the two hemispheres, as modeled ozone responses to trace gas and solar forcings are largely symmetric (WMO, 1999), though our modeling indicates that circulation changes may have accounted for a very small portion of the NH trend. The interhemispheric differences can be accounted for by the large increase in tropospheric ozone pollution in the $\mathrm{NH}$, whereas the $\mathrm{SH}$ remained relatively pristine. The $\mathrm{SH}$ record therefore reflects primarily a decrease in stratospheric ozone, while the $\mathrm{NH}$ trend indicates that the increase in tropospheric ozone there is comparable to stratospheric depletion. We therefore treat the two hemispheres as largely independent data sets.

Lastly, two sparse sets of measurements of ozone in the troposphere are available prior to the mid-1970s. Surface observations from 6 sites in Europe taken from the late 1930s to the 1950s (Staehelin et al., 1994) can be compared with observations at similar sites in Europe taken during the 1970s (Logan, 1985; Low et al., 1992). Ozonesonde data from the late 1960 s to the early 1980s are available from 8 midlatitude stations in the $\mathrm{NH}$, and 1 station in the $\mathrm{SH}$, and have been used previously for trend analyses (Logan, 1985). 
Table 2. Modeled mid-latitude stratospheric ozone column changes (DU)

\begin{tabular}{lcc}
\hline Forcing & 1957-1975 trend & 1850-1975 trend \\
\hline $\mathrm{N}_{2} \mathrm{O}$ & -0.2 & -0.7 \\
Solar irradiance $^{a}$ & -1.2 & +0.5 \\
Halogens $^{b}$ & -1.8 & -1.8 \\
Temperature $^{c}$ & -0.1 & -0.2 \\
Water vapor $^{d}$ & -4.5 & -7.2 \\
All except water $^{e}$ & -3.9 & -2.1 \\
All $^{e}$ & -8.3 & -9.1 \\
\hline
\end{tabular}

a 2-D and GCM 15\% different here, circulation related.

$b$ Nearly all the halogen-induced depletion took place between 1970 and 1975.

${ }^{c}$ In GCM only. The temperature change due to greenhouse gas increases is negative in the middle and upper stratosphere, but in the lower stratosphere, we see a warming related to dynamics in the troposphere which extends into the lowermost stratosphere. Thus the temperature change leads to less ozone in the lower stratosphere, and more ozone higher up. This cancellation gives us the relatively small overall column impact. A 2-D chemistry model, that would not have been able to capture the dynamical response to increased GHGs seemed to give a larger response of ozone to increased $\mathrm{CO}_{2}$ (WMO, 1999), presumably due to radiative cooling throughout the stratosphere.

${ }^{d}$ Including -0.9 and -2.5 from methane oxidation for 1957-1975 and 1850-1975, respectively. The sensitivity of ozone to increased water vapor is broadly consistent with that seen in a 2-D model (Dvortsov and Solomon, 2001).

${ }^{e}$ Total trends are not equal to the sum of the individual forcings due to nonlinearities in the chemical system.

\section{Use of the data to constrain reactive GHG trends}

We evaluate 1957-1975 trends from all the data, beginning with the stratosphere. Increased stratospheric water vapor leads to increased production of hydrogen oxides, which catalytically destroy ozone, so that the behavior of ozone and water is coupled (hydrogen oxides also affect ozone by altering the partitioning of reactive nitrogen and chlorine species). The observed increase in water vapor therefore implies a decrease in stratospheric ozone, as does the strong negative trend in the SH ozone column observations. The Goddard Institute for Space Studies (GISS) general circulation model (GCM) with parameterized stratospheric chemistry and the GISS 2-D photochemical model (Shindell et al., 1998; Shindell, 2001), both updated to the most recent laboratory data (Sander et al., 2000), and validated against satellite observations (Shindell, 2001), are used to infer trends from these two data sets. Intermodel differences were within $10 \%$, except as noted. The 2-D model contains 44 molecules and 131 reactions important for stratospheric ozone, including het- erogeneous reactions. The parameterization of stratospheric chemistry used in the GCM was derived from this 2-D model. The parameterized stratospheric chemistry calculates ozone anomalies, which are then added to the GCM's ozone climatology to derive the ozone field. Only the ozone anomalies are transported by the GCM, which does this using climatological meteorology fields (i.e. any circulation changes do not affect ozone transport, as circulation changes are not included in this study). Transport of the background ozone amounts is implicit in the time-varying climatology. The GCM version used here for the stratospheric simulations has 23 vertical layers extending to $\sim 85 \mathrm{~km}$ altitude, and has a horizontal resolution of 8 degrees latitude by 10 degrees longitude (Rind et al., 1998). The model uses a secondorder moments scheme for transport of heat, moisture and momentum, however, giving it effectively higher resolution. The model also contains a parameterized gravity-wave drag scheme in the stratosphere, enabling it to give a realistic climatology of winds and temperatures.

Stratospheric ozone changes were calculated for the 1957-1975 period based on changes in the factors controlling the ozone budget: nitrogen oxides, temperature, hydrogen oxides, halogens, and solar irradiance. Nitrogen oxide abundance changes were calculated from trends in its primary source gas, $\mathrm{N}_{2} \mathrm{O}$, which has been well measured (IPCC, 2001). Temperature changes were based on previous GCM simulations driven by observed increases in greenhouse gases, which tended to cool the stratosphere (Shindell, 2001). Methane increases were also based on observations (IPCC, 2001). These generate hydrogen oxides, and also alter the partitioning of chlorine species. Halogens trends were based on observed CFC trends (IPCC, 2001). While halogen abundance grew to very large levels during the late 1970s and the 1980s, the increase up to the mid-1970s also had some influence on stratospheric ozone. While using the period from 1957 until 1970 would have removed nearly all trace of halogens, we felt that it was a worthwhile tradeoff to include the additional years of the early seventies, when halogen loading was still fairly small, to obtain more reliable trend estimates.

Solar irradiance trends were based on a reconstruction (Lean et al., 1995). The 1957 to 1975 time frame began near a maximum in the $\sim 11$-year solar cycle, and ended near a minimum, so that there was an overall decrease over this particular period as part of the cyclic behavior of solar output. Variations in volcanic aerosol were not included, since although there was a significantly higher aerosol loading for a few years in the mid-1960s, there should have been little impact on the overall trend as the loading in both the late 1950s and mid-1970s was quite small (Sato et al., 1993). Changes in circulation were also neglected, as these have not been quantified. Water vapor changes were prescribed based on the observations discussed above (the contribution from methane oxidation alone was also calculated). Uncertainty in the calculated ozone trends arises predominantly from water vapor, which has the largest impact and also a large mea- 
Table 3. Observed Northern mid-latitude summer surface ozone (ppbv)

\begin{tabular}{|c|c|c|c|c|c|}
\hline Station & Altitude $^{a}$ & $\begin{array}{c}\text { Pre-1960 } \\
\text { ozone }^{b}\end{array}$ & Station & Altitude $^{a}$ & $\begin{array}{c}\text { 1970s } \\
\text { ozone }^{b}\end{array}$ \\
\hline Arkona & 0 & 16 & Arkona & 0 & 31 \\
\hline Lauterbrunnen & 800 & 17 & Garmisch-Partenkirchen & 740 & 43 \\
\hline Chamonix & 1000 & 21 & Hohenpeissenberg & $900 \mathrm{mb}$ & 33 \\
\hline Pfaender & 1000 & 16 & Payerne & $900 \mathrm{mb}$ & 41 \\
\hline Fichtelberg & 1200 & 18 & Fichtelberg & 1200 & 28 \\
\hline Arosa & 1800 & 25 & Wank Peak & 1800 & 39 \\
\hline Average & & 18 & Average & & 37 \\
\hline
\end{tabular}

${ }^{a}$ Altitudes are estimated to the nearest $100 \mathrm{~m}$, except for sonde data for which they are given in pressure $(900 \mathrm{mb} \sim 1000 \mathrm{~m})$.

$b$ Values are observations prior to 1960 (Staehelin et al., 1994) and during the 1970s (Logan, 1985; Low et al., 1992).

surement uncertainty. To characterize this, we use the +0.03 to $+0.08 \mathrm{ppmv} / \mathrm{yr}$ range from lower stratospheric in situ observations (Rosenlof et al., 2001), as the increase at these altitudes dominates the ozone column impact.

The modeled changes in the stratospheric ozone column due to each factor are given in Table 2. A twenty year run with 1975 conditions is compared with a twenty year 1957 control simulation. An additional run without the water vapor changes was also performed. The model diagnostics record the effect of each factor in the ozone budget. Including increased water vapor, the ozone trend from 1957 to 1975 is $-8.3 \pm 4.0 \mathrm{DU}(-8.2$ in the GCM, -8.4 in the 2-D model). This value is quite consistent with the value obtained from the SH total column data of $-9.6 \pm 6.6 \mathrm{DU}$. The agreement is maintained if values from the coupled tropospheric chemistry-climate model are used to remove the tropospheric portion of the SH column data. Those model results, discussed further below, gave a tropospheric increase of $1.1 \pm$ $0.6 \mathrm{DU}$ in the SH. Stratospheric change inferred from the column is then $-10.6 \pm 6.6 \mathrm{DU}$, still in good agreement with the stratospheric chemistry model. This suggests that significant stratospheric ozone depletion may have taken place before the CFC induced depletion of the 1980s and 1990s, in large part because the stratosphere appears to have become progressively wetter during that period (Table 2).

We now examine the behavior of tropospheric ozone. Tropospheric column increases of $0.9 \pm 0.8 \% \mathrm{yr}^{-1}$ were seen at eight northern mid-latitude ozonesonde stations from the late 1960s to the early 1980s (Logan, 1985). The sonde trends do not coincide perfectly with the time of interest, and would likely have been slightly larger, at least over North America, prior to mid-1970s pollution controls (Logan, 1985), so we adopt a trend of $1.1 \% \mathrm{yr}^{-1}$ for our estimate, well within the uncertainty range. Assuming this same trend back to the late 1950 s, and a tropospheric ozone column of about $30 \mathrm{DU}$ in the mid-1970s, this yields an increase of $6.0 \pm 5.3 \mathrm{DU}$ extended over the 1957-1975 period. Note also that the sonde data support the idea that tropospheric ozone increased much more slowly in the $\mathrm{SH}$, as observations from Aspendale, the only SH mid-latitude station reported, show no statistically significant trend even at the 1-sigma level. Thus it appears that NH column trends may reflect partially offseting stratospheric decreases and tropospheric increases. Indeed, a suggestion of such opposing trends has been noted by previous authors based on early European sonde measurements (Staehelin et al., 1998).

Another source of information on tropospheric ozone increases comes from comparing summer surface measurements taken over Europe from the late 1930s to the 1950s (Staehelin et al., 1994) with observations taken in the mid1970s (Logan, 1985) (Table 3). While these data primarily reflect boundary layer concentrations, some of the observations were taken at mountaintop observatories, and therefore give us an indication of conditions within the free troposphere. As with sonde measurements, these data show large increases in the $\mathrm{NH}$ at mid-latitudes, of $17 \pm 5.6 \mathrm{ppbv}$ for the six stations shown in Table 3 with observations available at both times at similar locations and altitudes.

We have used results from a coupled chemistry-climate simulation with the GISS GCM (Shindell et al., 2001) to infer tropospheric trends from the surface changes. The GCM version used for the tropospheric chemistry-climate runs has 9 vertical layers and a horizontal resolution of 4 by 5 degrees, and contains an online calculation of chemistry related to tropospheric ozone (rather than a parameterization such as was used for stratospheric chemsitry). The difference between preindustrial and present-day simulations (which is similar to that seen in other models; Shindell et al., 2001) was used to represent the geographic distribution of anthropogenically induced changes in tropospheric ozone. Changes in anthropogenic emissions can best be prescribed at these two times, as they have been well characterized for the 1990s (Graedel et al., 1993), and most were zero in the preindustrial era, whereas in between these times, emissions are not well known (the very recent publication of inventories by van Aardenne et al., 2001 will enable more realistic 


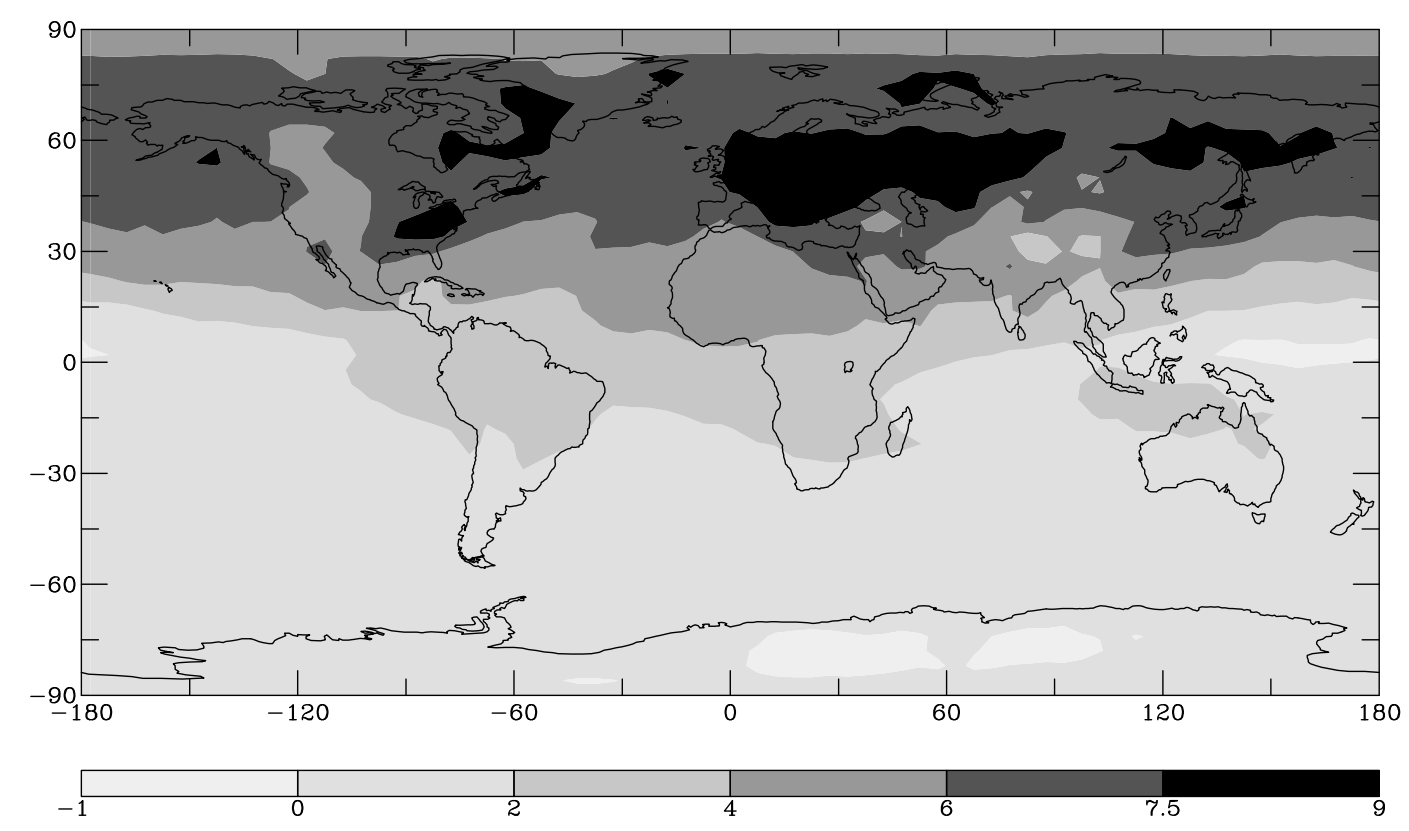

Fig. 1. Tropospheric ozone column change from 1957 to 1975 . A modeled distribution of the anthropogenic impact on tropospheric ozone has been scaled to match observed surface increases from the 1950 s to the 1970 s, as described in the text.

simulations of ozone's time-dependent evolution to be performed in the future). Large uncertainties remain even for the preindustrial, however, as emissions of ozone precursors from biomass burning and natural emissions of non-methane hydrocarbons are not well quantified. This modeled distribution of anthropogenic ozone change in the troposphere was then scaled so that the model's summertime values match the observed mean surface values over Europe during the 1950s and the mid-1970s. This assumes that the spatial pattern of anthropogenic ozone increases in the troposphere does not vary significantly with time (i.e. that proportional rates of industrial emissions were broadly constant around the world, assuming these are subsequently spread out over large areas, especially in the zonal direction), so that the model's distribution can essentially be used to fill in areas with no data. Tropospheric column trends from the difference between the two scaled distributions (Fig. 1), using all land grid boxes from 20 to 50 degrees, are $7.7 \pm 1.8 \mathrm{DU}$ for the $\mathrm{NH}$, and $1.1 \pm 0.4 \mathrm{DU}$ for the SH. Including the uncertainty in the mean observed surface change, they are $7.7 \pm 3.1 \mathrm{DU}$ for the $\mathrm{NH}$, and $1.1 \pm 0.6 \mathrm{DU}$ for the $\mathrm{SH}$ (used previously in the stratospheric ozone discussion). Using only grid boxes containing the observing stations gave results within $5 \%$ of these values, as the model's $4 \times 5$ degree resolution considerably smooths the variability of the tropospheric ozone field. Inferring column values from surface data is possible since the model's vertical structure of ozone changes is realistic. Modeled changes decrease very slowly from the surface up to $\sim 600 \mathrm{mb}$, then more rapidly, decreasing to only $20 \%$ of the boundary layer value by $250 \mathrm{mb}$, and to near zero by
$150 \mathrm{mb}$. This agrees quite well with observed changes from the late 1960s through the late 1970s or early 1980s (Logan, 1985). Of course since this is an indirect determination from a limited set of data (some of which are slightly mismatched in time), our confidence in this individual trend value is very low.

Tropospheric ozone changes can also be inferred from the NH column trend minus the mean stratospheric change. The column data come from both urban (but screened to $<3$ million 1975 population, see Appendix) and rural continental sites. These were largely located in the same geographic areas as the ozonesonde stations, namely eastern and central North America, central Europe, and Japan, where observations came from the same three stations as for the sonde data (no sonde data from the Indian subcontinent were available). Increases in $\mathrm{SO}_{2}$ cause a small positive bias in polluted, urban areas, which we estimate to be $1.0 \pm 1.0 \mathrm{DU}$ averaged over all NH stations (WMO, 1995), and remove from the trend.

The combination of $\mathrm{NH}$ mid-latitude tropospheric ozone changes derived from total column data, ozonesondes, and surface measurements allows us to better constrain the mean change in NH tropospheric ozone. This can then be used to revise the stratospheric trend estimated from $\mathrm{NH}$ column minus $\mathrm{NH}$ tropospheric change, which in turn allows us to improve the estimate of the multisource stratospheric trend, so that iteratively we arrive at the mean and 2-sigma uncertainties based on all five data sets (Fig. 2). By weighting the mean according to the inverse square of the uncertainty of each data set, the final result is proportionately less af- 


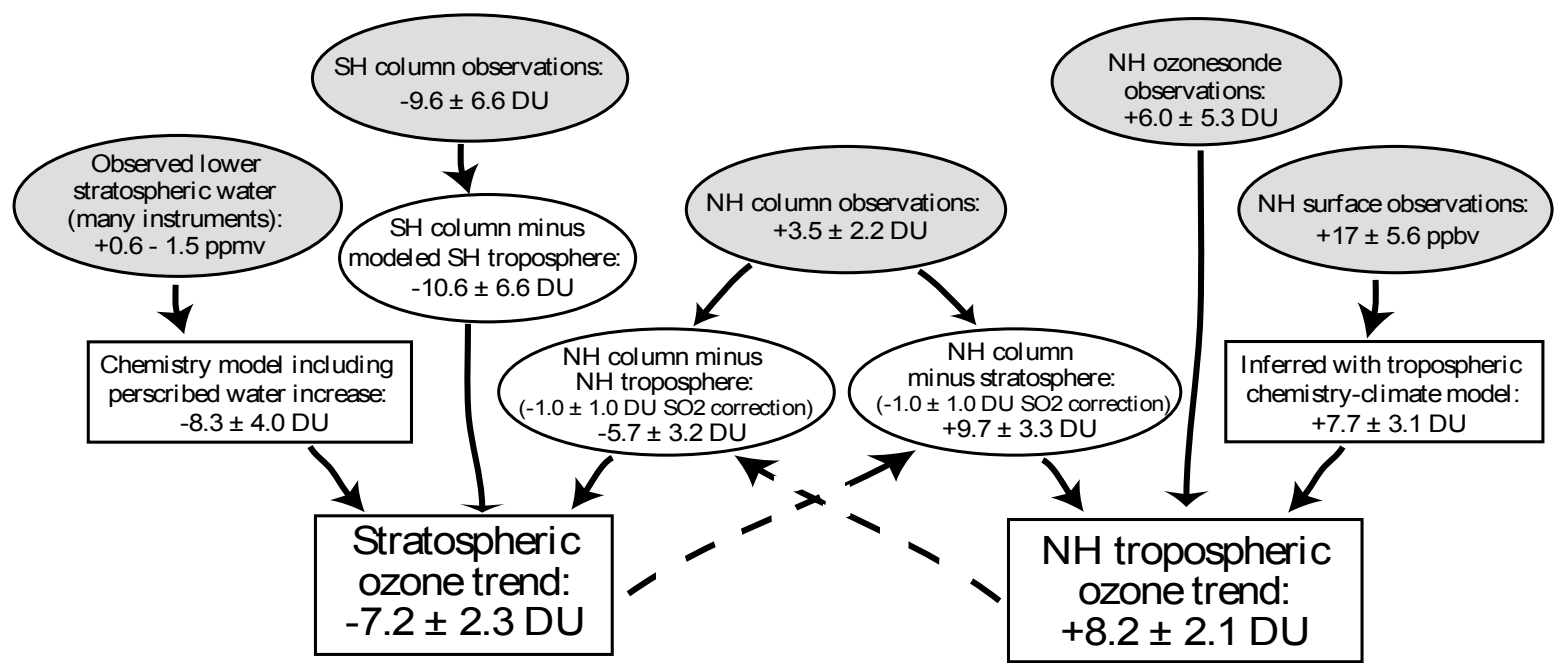

Fig. 2. NH mid-latitude ozone trends from 1957 to 1975 and their 2-sigma uncertainty using our multisource approach. Values based directly on observations are shown in shaded ovals, values derived primarily from data are in open ovals, while those from data driven models are in open rectangles. The final trends are shown in the lowest rectangles, and were calculated iteratively due to interactions between trends in the troposphere and stratosphere (shown by dashed arrows). Mean values and standard deviations are based upon uncertainty weighted calculations (i.e. weighted by the inverse square of the uncertainty). Tropospheric trends are calculated over land.

fected by the more uncertain values, such as the SH column observations which are based on only four stations. The final values upon convergence of the iteration are $-7.2 \pm 2.3$ DU for the stratospheric trend, and $8.2 \pm 2.1 \mathrm{DU}$ for the $\mathrm{NH}$ continental trend. Clearly, only with the use of multiple, independent data sets are the results more than marginally significant, demonstrating the usefulness of this multisource approach over more limited evaluations.

Observations of stratospheric water, total column ozone, and tropospheric ozone therefore overconstrain the reactive greenhouse gases (except for tropospheric water), allowing us to develop a complete scenario for their evolution from the 1950s to the 1970s. The available data sets, however, are subject to valid criticisms, especially as to their spatial and temporal coverage, but there is unfortunately no other data available. Since there are no known ways to extract historical values for the reactive greenhouse gases, these limited data are all we have to work with. However, the consistency of the five data sets with each other and with the model results lends credence to the trends presented here. While by no means definitive, it is reasonable to evaluate these proposed long-term trends not only against the evidence for their existence, as presented here, but also against the evidence for the standard, default assumption that the abundance of these gases, especially stratospheric ozone, did not greatly change from the mid-1950s to the mid-1970s. The little data available do appear to indicate significant changes. Thus while this reevaluation of changes in ozone and in stratospheric water vapor relies upon sparse data, and therefore our confidence in the exact values derived here is low, it nevertheless seems the most plausible scenario yet developed.

\section{Extension back in time}

Assuming that the 1950s to 1970 s trends derived here are at least qualitatively realistic, they indicate that long-term changes in stratospheric ozone and water vapor prior to halogen induced depletion were largely driven by GHG and solar irradiance changes. This suggests that these same factors may have induced trends prior to the $1950 \mathrm{~s}$ as well. To explore this possibility, we extend the stratospheric ozone trends throughout the industrial era again based on modeling driven by observed trends in the long-lived GHGs (IPCC, 2001) and reconstructed solar irradiance (Lean et al., 1995), as no direct observations are available.

Increased water vapor results from increased methane, and from greater transport from the troposphere to the stratosphere. The latter seems likely to have been caused by increased residual circulation (Zhou et al., 2001) which is probably related to the long-term buildup of GHGs, as GCMs produce increased circulation in response to increased GHGs (Rind et al., 1998; Butchart and Sciafe, 2001). An additional possibility is that industrial pollution has reduced rainfall (Rosenfeld, 2000) (in accord with observations in the subtropics, but opposite to observations in the tropics), increasing the abundance of tropospheric water vapor, which can be the limiting factor in transport to the stratosphere in some seasons. In either case, we can then assume that water vapor and ozone changes were largely driven by anthropogenic activities.

The water vapor trend due to increased methane oxidation can be straightforwardly calculated from the historical methane trend using the photochemical model. The resultant 
increase in water vapor since the preindustrial is about 1.3 ppmv in the lower stratosphere. The water vapor increase due to transport can be estimated by scaling the observed transport-related increase (that portion of the observed increase that cannot be accounted for by increased methane oxidation) by carbon dioxide changes, the presumed main driver of the increase. While there is no guarantee that change in water vapor transport varied linearly with $\mathrm{CO}_{2}$ back into the past, observations over the past 4 to 5 decades do not suggest strong long-term non-linearity (Rosenlof et al., 2001). Carbon dioxide increased by about $30 \%$ from 1850 to 2000 , versus $20 \%$ from 1954-2000 (during which the observed water vapor increase due to transport appears to have been about $1.4 \mathrm{ppmv}$ ). Thus the total water vapor increase from 1850 to the present would have been about 3.4 ppmv in the stratosphere, with $2.1 \mathrm{ppmv}$ from transport and $1.3 \mathrm{ppmv}$ from methane oxidation. Assuming the same 45\% uncertainty as in the 20th century observations gives a trend of $3.4 \pm 1.5$ ppmv. Note that while the transport-related increases are assumed to be roughly uniform with altitude above the tropopause, methane oxidation produces relatively little water vapor near the tropopause, where the radiative impact is largest, though its production increases sharply with altitude above that region. Values given here are representative of the water increase due to methane oxidation several $\mathrm{km}$ above the tropopause, where it is fairly large, but its radiative impact will be smaller than for transport-induced increases. Given the uncertainties in these estimates of water vapor changes, we also investigate the ozone changes excluding variations in water vapor, as for the 1957-1975 period.

The modeled stratospheric ozone trend for $1850-1975$ is $-9 \pm 4$ DU (Table 2), almost the same as that calculated for the 1957-1975 period. Thus we believe that stratospheric ozone changes took place primarily during the latter half of the twentieth century. Additionally, these long-term trends suggest that greenhouse gases (via $\mathrm{N}_{2} \mathrm{O}$ and water) may affect future ozone recovery.

Minimal quantitatively reliable data are available to extend tropospheric trends back in time. Nineteenth century surface observations are the only data available for the reactive GHGs (Volz and Kley, 1988; Marenco et al., 1994; Sandroni and Anfossi, 1994; Pavelin et al., 1999). There are many questions about the quantitative reliability of these data, however, other than for the measurements from Montsouris (Volz and Kley, 1988). As an exercise, we can scale our modeled preindustrial to present-day change to match these purported observations. The GCM does reproduce the observed relationship between surface ozone and the rest of the troposphere, as noted previously. The scaling required to reproduce the observed values of around $10 \mathrm{ppbv}$ at 16 locations covering wide areas of both hemispheres is 1.5 . This would yield inferred 1850 to 1975 tropospheric increases of 15 and 4 DU over the polluted continental NH and SH, respectively.

\section{Climate impacts}

To explore the climatic effects of these potential ozone changes, we have calculated the tropopause radiative forcing from the multisource ozone trends using a stratospheretroposphere version of the GISS GCM with 4 by 5 degree horizontal resolution and 31 vertical layers. Forcings due to stratospheric ozone are adjusted, while tropospheric forcings are instantaneous. Note that the stratospheric ozone radiative forcing is not purely a 'forcing' in the traditional sense of being attributable to a particular change external to the climate system, as increased water vapor may be partially due to climate feedbacks. Similarly, the tropospheric ozone changes may have arisen partially from climate feedbacks such as changes in lightning or in production of hydrocarbons from the biosphere, but we follow convention and calculate the total 'forcing' from ozone changes to be comparable with other works. Our reevaluated stratospheric trends were added to measured 1979-1997 losses, while for tropospheric ozone, we used the difference between the scaled 1950s global distribution and present-day climatology. Forcings for the mid1950 s to the present were $-0.15 \pm 0.05 \mathrm{~W} / \mathrm{m}^{2}$ for the stratosphere (versus $-0.10 \mathrm{~W} / \mathrm{m}^{2}$ using only the observed depletion after 1979 in the GISS model; Hansen et al., 2000) and $0.38 \pm 0.10 \mathrm{~W} / \mathrm{m}^{2}$ for the troposphere.

The effects of the changes extrapolated back to 1850 were also calculated, using the reactive GHG changes described above. The forcing was $-0.18 \pm 0.08 \mathrm{~W} / \mathrm{m}^{2}$ for the stratosphere. Recognizing the difficulty in ascribing uncertainty to trends based on sparse historical data, we assign a subjective confidence level (IPCC, 2001) of 'low' to the preindustrial to present-day stratospheric forcing. For the troposphere, the value is $0.7 \mathrm{~W} / \mathrm{m}^{2}$ when surface ozone is forced to $10 \mathrm{ppbv}$, similar to that calculated in other modeling experiments that disregarded the standard assumptions of preindustrial sources and instead forced ozone concentrations to match purported preindustrial surface observations (Kiehl et al., 1999; Mickley et al., 2001), and near the high-end value of $0.77 \mathrm{~W} / \mathrm{m}^{2}$ calculated without tropospheric chemical production in the preindustrial (Hauglustaine and Brasseur, 2001).

The stratospheric ozone forcing is slightly larger than other estimates (Hansen et al., 2000; IPCC, 2001) (at least those using the latest ozone change profile; WMO, 1999), which assumed no stratospheric loss prior to the 1970s. Radiative forcing from tropospheric ozone was likely small, but non-zero prior to the 1950s. Anthropogenic nitrogen oxide emissions approximately doubled, increasing by about 10 $\mathrm{Tg} / \mathrm{yr}$ from 1890 to 1957 versus an increase of about $20 \mathrm{Tg} / \mathrm{yr}$ from 1957 to 1990 (van Aardenne et al., 2001). If the ozone change and forcing were to follow the nitrogen oxides, one of its most important precursors, this would suggest an additional forcing of around $0.2 \mathrm{~W} / \mathrm{m}^{2}$, for a total tropospheric ozone forcing from the preindustrial to the present of about $0.6 \mathrm{~W} / \mathrm{m}^{2}$. In any case, our multisource tropospheric ozone 
forcing from the $1950 \mathrm{~s}$ to the present $\left(0.38 \mathrm{~W} / \mathrm{m}^{2}\right)$, combined with any plausible estimate of forcing prior to the 1950s, is near or exceeds the high end of current preindustrial to present-day estimates from chemistry-climate models driven by the standard assumptions for preindustrial emissions (giving a forcing of $0.35 \pm 0.15 \mathrm{~W} / \mathrm{m}^{2}$; IPCC, 2001).

\section{Summary and conclusion}

The historical behavior of the short-lived greenhouse gases ozone and water vapor prior to the coincident large increase in stratospheric halogen loading and arrival of satellite observations is not well-known. Using newly available data, we have studied their evolution prior to halogen-induced ozone depletion. Although data coverage is poor, the coupled atmospheric system is more tightly constrained than individual trends, allowing changes to be estimated with greater confidence. The scenario that yields optimal consistency with all the available mid-latitude data during 1957-1975 is: a stratospheric ozone decrease of 5-10 DU, tropospheric ozone increases of about 1 DU in the Southern Hemisphere and 6-10 DU in the Northern Hemisphere, and stratospheric water vapor increases of about $0.8-1.0 \mathrm{ppmv}$. The results suggest that twentieth century stratospheric ozone depletion may have been roughly $50 \%$ more than is generally supposed, but not clearly visible in the early column data due to the offsetting effect of increasing tropospheric ozone pollution.

The radiative forcing due to the stratospheric ozone changes would have been about $-0.15 \mathrm{~W} / \mathrm{m}^{2}$ since the 1950 s, while that due to tropospheric ozone would have been about $0.4 \mathrm{~W} / \mathrm{m}^{2}$. The latter value is near the high end of the forcing derived from models for the entire industrial era, and is nearly half the $0.9 \mathrm{~W} / \mathrm{m}^{2}$ from $\mathrm{CO}_{2}$ since the $1950 \mathrm{~s}$, suggesting that ozone may have played a larger role in recent global warming than previously believed. Of course regional variations in the forcing due to inhomogeneous gases such as tropospheric ozone are much larger than that for longlived GHGs, so that this comparison tells only part of the story. The results suggest that alternative scenarios for slowing global warming via controls on tropospheric ozone and methane (Hansen et al., 2000) may be quite useful (though the relative importance of $\mathrm{CO}_{2}$ is likely to increase in the 21 st century). Furthermore, tropospheric ozone is harmful to human health and agriculture, so that reductions are highly desirable.

Additionally, under the scenario proposed here, past radiative impacts of GHGs plus ozone may have been more positive than previously believed. This implies that the role of aerosols in offsetting the GHGs may be towards the high end of current estimates (the uncertainty of the indirect effect of aerosols is large enough to encompass significant changes in this value). This would leave us with a troubling situation, where we are forced to either continue our emissions of pol- lutant aerosols over the long lifetime of the GHGs, or to face a greater portion of the GHG induced warming if we reduce the emissions of the short-lived aerosols.

Though no additional measurements can be taken of historical ozone and water vapor, new or improved analyses such as the recent studies of stratospheric water vapor and our analysis of the total column ozone data may appear in the future. Such studies might improve the reliability of historical trends estimates. Until then, however, the present estimates take into account all available relevant data, and thus provide a potential reconstruction of past trends in the radiatively and chemically active trace gases ozone and water which is otherwise unavailable. While the trends derived here are quite uncertain due to the data limitations, at minimum, they give an idea of how much the default assumptions (no stratospheric trend prior to 1980, tropospheric trends from models) may be in error, and emphasize the importance of gaining a better understanding of these historical trends.

\section{Appendix A: Analysis of 1957-1975 ozone column data}

Column ozone data were obtained from the World Ozone Data Center in Toronto. Station data used in calculating trends were summarized in Table 1 . The seasonal cycle was removed from all stations prior to analysis, which was preformed using the least-squares technique on annual mean data. Stations located in very large metropolitan areas (> 3 million population in 1975, which includes New Delhi and Buenos Aires) were not used, as these are not likely to be representative of larger scale trends. Stations at all altitudes were included. For the 'best estimate' case, the data at each station were screened as follows: we required that a minimum of forty percent of the years during the chosen time period contain data, and a maximum standard deviation of 8 Dobson units (DU) per decade (16 DU over the entire period) in the least-squares regression was allowed, to eliminate stations with less reliable data, assuming that very large variability was related to measurement problems. Additionally, the analysis was restricted to the 20 to 55 degree latitude bands in each hemisphere, as data were most abundant in these regions. We judged it preferable to obtain the most accurate value for mid-latitudes for comparison with the model, rather than to include data from the tropics and polar regions, where coverage is extremely sparse, and the behavior of the reactive GHGs can be somewhat different. As in the main text, we use 2-sigma uncertainties throughout this Appendix (except for trends at individual stations, for which we give 1-sigma uncertainties as in Table 1).

There are known problems with some archived data. We have corrected for Kagoshima data being 9 DU too low from November 1963 to July 1967, and during the 1970s (WMO, 1999). The Macquarie Island instrument was changed in 1962 and again in 1972, and other minor corrections have 
Table 4. Total column trend estimates for alternative selection criteria

\begin{tabular}{lcccccc}
\hline & Time & $\begin{array}{c}\text { Minimum } \\
\text { Coverage }\end{array}$ & $\begin{array}{c}\text { Maximum } \\
\text { station } \\
\text { variance }\end{array}$ & latitudes & $\begin{array}{c}\text { SH trend } \\
\text { \& 2-sigma } \\
\text { uncertainty }\end{array}$ & $\begin{array}{c}\text { NH trend } \\
\text { \& 2-sigma } \\
\text { uncertainty }\end{array}$ \\
\hline Best estimate & $1957-1975$ & $40 \%$ & 16 & $20-55$ & $-9.6 \pm 6.6$ & $3.5 \pm 2.2$ \\
& $1957-1975$ & $\mathbf{2 0 \%}$ & 16 & $20-55$ & $-9.6 \pm 6.6$ & $3.5 \pm 2.2$ \\
& $1957-1975$ & $\mathbf{6 0 \%}$ & 16 & $20-55$ & $-8.3 \pm 7.0$ & $2.4 \pm 2.4$ \\
& $1957-1975$ & $40 \%$ & $\mathbf{2 0}$ & $20-55$ & $-10.1 \pm 6.4$ & $3.4 \pm 2.2$ \\
& $1957-1975$ & $40 \%$ & $\mathbf{1 2}$ & $20-55$ & $-8.3 \pm 7.0$ & $3.4 \pm 2.2$ \\
& $1957-1975$ & $40 \%$ & 16 & $\mathbf{2 0 - 5 0}$ & $-9.8 \pm 6.8$ & $1.9 \pm 2.4$ \\
& $1957-1975$ & $40 \%$ & 16 & $\mathbf{3 0 - 5 5}$ & $-10.3 \pm 9.4$ & $2.4 \pm 2.4$ \\
& $1957-1975$ & $40 \%$ & 16 & $\mathbf{2 0 - 6 0}$ & $-9.6 \pm 6.6$ & $3.5 \pm 2.2$ \\
& $\mathbf{1 9 5 9 - 1 9 7 5}$ & $40 \%$ & 16 & $20-55$ & $-6.4 \pm 6.4$ & $2.5 \pm 2.2$ \\
$\begin{array}{l}\text { Altitudes } \\
\text { 0-1500 m }\end{array}$ & $\mathbf{1 9 5 7 - 1 9 7 3}$ & $40 \%$ & 16 & $20-55$ & $-8.6 \pm 7.0$ & $4.9 \pm 2.4$ \\
Removing & $1957-1975$ & $40 \%$ & 16 & $20-55$ & $-9.6 \pm 6.6$ & $4.5 \pm 2.6$ \\
corrected & $1957-1975$ & $40 \%$ & 16 & $20-55$ & $-9.6 \pm 6.6$ & $4.0 \pm 2.4$ \\
stations & & & & & & \\
\hline
\end{tabular}

Bold face is used to highlight the parameter changed in each test. Maximum station variance gives the maximum 1-sigma standard deviation allowed for the trend estimate over the entire 19 year period. Minimum coverage gives the percentage of years containing data required.

been noted there (Lehmann, 1994). Though we did not remove data from any other stations, we have only used data from 1963-1972 taken with a single instrument for Macquarie Island, choosing to be extra cautious in the data-poor SH. However, we note that though the 1957-1959 data are high, it is not clear that they are systematically biased. For example, both 1958 and 1964 are years containing data for each month. The 1958 data are within 5 DU of the 1964 data in 4 months, and the 1958 data falls within the range of that seen in later years in 9 months. If all data prior to 1972 are used, the negative trend becomes much larger $(-24.3 \pm$ 10.2 (1-sigma) DU). A similar value is obtained adding in the 1973-1975 data, which yields a trend of $-21.6 \pm 7.6$ (1-sigma) DU. Using the latter trend in the best estimate case would change the overall result to $-11.8 \pm 6.2 \mathrm{DU}$, well within the uncertainty of the 1963-1972 trend used here.

After correcting these known problems, we carefully inspected the data by hand to look for obvious discontinuities during the early portions of the measurements ('jumps' in the data). Though a great many observational groups have contributed data to the center, a great deal of effort will still be required to make this data more useful to the wider community by correcting problems. Our present analysis could likely be improved upon by selecting for ozone data which maintained its short-term correlation with local meteorology (e.g. $100 \mathrm{hPa}$ temperatures) throughout the observational period, though this would require a very thorough analysis of the ozone/meteorology relationship beyond the scope of this paper. We discovered numerous systematic biases, which we corrected to remove the spurious trends which would other- wise result (and may account for some of the very large trend estimates calculated during the 1970s). Discontinuities were adjusted by removing the difference between the early data and the same months in the subsequent one or two years. The biases were: Kagoshima data 13 DU too high prior to 1961 , Srinagar data 32 DU too low prior to 1963, Quetta data 61 DU too low prior to March 1958, and Bismarck data $31 \mathrm{DU}$ too low prior to February 1958 (both New Delhi and Buenos Aires also exhibited sharp discontinuities, giving another reason to exclude them from the trend estimations). To test the influence of the adjusted NH data, we repeated the "best estimate" analysis excluding all data that had been adjusted. The $\mathrm{NH}$ trend was then $4.0 \pm 2.4 \mathrm{DU}$, quite similar to the $3.5 \pm$ 2.2 DU trend when the adjusted data is included.

A least-squares regression was performed on the corrected annually averaged data from each station meeting our criteria, and hemispheric averages and uncertainties were calculated weighting the data according to the trend confidence level at each station. We chose not to use a multiple linear regression model as we have already removed short-term seasonal variability, and longer-term variability is either weak, or accounted for in other ways. Variability due to the QBO largely averages out over the 19 years of our trend analysis. In a multiple regression, it only accounts for around $0.5 \mathrm{DU}$ over two decades (Chandra et al., 1996) in any case. Long term variability from the sun is accounted for in the chemical model, so we include it in the trend for a proper comparison. Since solar impacts are not necessarily linear, we believe that this method is as useful as multiple linear regression. We are thus able to demonstrate that the data reveal trends even 
with minimal processing. We note that our conclusion that column ozone was increasing at NH mid-latitudes prior to 1975 is consistent with earlier analysis covering the period 1964-1975 using a multiple regression model (Krzyscin, 1994). Many choices for screening criteria were evaluated. Selection criteria that were a great deal more restrictive than the 'best estimate' excluded so many stations that the hemispheric trends were much more uncertain, as did much less restrictive criteria, due to the inclusion of stations with extremely large variability.

To test the influence of the selection criteria, we reanalyzed the data using perturbations about the optimal criteria: (a) varying the minimum fraction of years from $40 \%$ to $20 \%$ and $60 \%$, (b) varying the maximum standard deviation in the least-squares regression computed at the individual stations from 16 to 12 and 20 DU over the trend period, (c) varying the latitude and altitude ranges, and (d) varying the time period for the analysis. These sensitivity tests gave trend estimates all within the 2-sigma confidence interval for the best estimate (Table 4). The derived trends are thus relatively robust to the data selection process (the key factors, a significant negative trend in the $\mathrm{SH}$ and a significant positive trend in the NH-minus-SH difference are always present). We point out that while the first two years of the data record show high values at many stations, excluding 1957 and 1958 alters the NH trend by a smaller amount than excluding the last two years. Though the first two years have a larger effect in the $\mathrm{SH}$, their exclusion gives a trend still within the confidence interval of the best estimate. The result that exclusion of the high altitude stations gives a larger NH trend is consistent with reduced pollution at high altitudes. The mean trend using only the six NH stations located above $1500 \mathrm{~m}$ is +0.0 DU, suggesting that the stratospheric loss and tropospheric pollution are largely balanced above the polluted boundary layer. For the 'best estimate' criteria, the NH mid-latitude trend over the period 1957-1975 was $3.5 \pm 2.2 \mathrm{DU}$, while for the SH it was $-9.6 \pm 6.6 \mathrm{DU}$. Averaging all twelve test analyses yields similar trends, namely $3.3 \pm 2.3 \mathrm{DU}$ for the $\mathrm{NH}$ and $-9.2 \pm 6.9 \mathrm{DU}$ for the $\mathrm{SH}$.

There is considerable station-to-station variability, especially in the NH. This results from the strong sensitivity of tropospheric ozone to local conditions. Yet the bulk of the stations show trends that are at least qualitatively similar to the overall hemispheric trends derived here. Only five of the thirty-one northern stations have negative values that are statistically significant. Two are Japanese stations (Sapporo and Tateno), which, along with the very weak, non-significant trend seen at Kagoshima, suggests that a local phenomenon may be responsible. Of the other stations with negative trends, one is a station whose data had to be corrected (Srinagar), while another has the minimum number of years to pass the selection criteria (Bracknell, with 9 years data), so that these stations are among the least reliable of the data set. Overall, most stations show a small increase or a statistically neutral trend, so that the 1-sigma standard deviation of the trend in 16 out of the 31 stations from $20-55^{\circ} \mathrm{N}$ overlaps with the best estimate $3.5 \pm 2.2 \mathrm{DU}$ mid-latitude trend given above, and the overlap is 25 out of 31 stations using 2-sigma uncertainties. Relaxing the selection criteria in the tests described above allowed four additional stations to pass the test. They were Churchill $\left(59^{\circ} \mathrm{N}\right)$, which showed a trend of -2.5 $\pm 10.2 \mathrm{DU}$ (1-sigma), Wallops Island $\left(38^{\circ} \mathrm{N}\right)$, which showed a trend of $-15.2 \pm 16.2$ DU (1-sigma), Lisbon and Aarhus. The latter two stations contained multiple data jumps that could not be easily corrected, however, so were not included.

In the SH, only four stations fit the selection criteria. All stations used the same instrument type throughout the measurement period, and every station shows a negative trend in total ozone (see Table 1). This suggests that the negative trend may be somewhat robust, though the uncertainty remains large due to the small sample size.

Acknowledgements. The authors thank Jim Hansen, Gavin Schmidt, and David Rind for comments, and NASA's Atmospheric Chemistry Modeling and Analysis Program for financial support.

\section{References}

Angell, J. K. and Korshover, J.: Global ozone variations: An update into 1976, Mon. Wea. Rev., 106, 725-737, 1978.

Bojkov, R. D., Bishop, L., and Fioletov, V. E.: Total ozone trends from quality controlled ground-based data (1964-1994), J. Geophys. Res., 100, 25 867-25 876, 1995.

Butchart, N. and Sciafe, A.: Climate change, stratospheretroposphere exchange, and chlorofluorocarbons, Nature, 410, 799-802, 2001.

Chandra, S., Varotsos, C., and Flynn, L. E.: The mid-latitude total ozone trends in the Northern Hemisphere, Geophys. Res. Lett., 23, 555-558, 1996.

Dvortsov, V. L. and Solomon, S.: Response of the stratospheric temperature and ozone to past and future increases in stratospheric humidity, J. Geophys. Res., 106, 7505-7514, 2001.

Graedel, T. F., Bates, T. S., Bouman, A. F., et. al.: A compilation of inventories of emissions to the atmosphere, Global Biogeochem. Cycles, 7, 1-26, 1993.

Hansen, J., Sato, M., Ruedy, R., Lacis, A., and Oinas, V.: Global warming in the twenty-first century: An alternative scenario, Proc. Natl. Acad. Sci., 97, 9875-9880, 2000.

Harris, N. R. P., Ancellet, G., Bishop, L., et al.: Trends in stratospheric and free tropospheric ozone, J. Geophys. Res., 102, 1571-1590, 1997.

Hauglustaine, D. A. and Brasseur, G. P.: Evolution of tropospheric ozone under anthropogenic activities and assocaited radiative forcing of climate, J. Geophys. Res., 106, 32 337-32 360, 2001.

Heath, D. F.: Non-seasonal changes in total column ozone from satellite observations, 1920-86, Nature, 332, 219-227, 1988.

Intergovernmental Panel on Climate Change: Climate Change 2001, (Eds) Houghton, J. T., et al., Cambridge University Press, Cambridge, England, pp. 881, 2001.

Johnston, H., Whitten, G., and Birks, J.: Effect of nuclear explosions on stratospheric nitric oxide and ozone, J. Geophys. Res., 78, 6107-6135, 1973. 
Kiehl, J. T., Schneider, T. L., Portmann, R. W., and Solomon, S.: Climate forcing due to tropospheric and stratospheric ozone, J. Geophys. Res., 104, 31 239-31 254, 1999.

Kley, D., Volz, A., and Mulheims, F.: in Tropospheric Ozone: Regional and Global Scale Interactions, (Ed) Isaksen, I. S. A., D. Reidel, Norwall, pp. 63-72, 1988.

Komhyr, W. D., Barrett, E. W., Slocum, G., and Weickmann, H. K.: Atmospheric total ozone increase during the 1960s, Nature, 232, 390-391, 1971.

Krzyscin, J. W.: Total ozone changes in the Northern Hemisphere mid-latitudinal belt $\left(30-60^{\circ} \mathrm{N}\right)$ derived from Dobson spectrophotometer measurements, 1964-1988, J. Atmos. and Terr. Phys., 56, 1051-1056, 1994.

Lean, J., Beer, J., and Bradley, R.: Reconstruction of solar irradiance since 1610: Implications for climate change, Geophys. Res. Lett., 22, 3195-3198, 1995.

Lehmann, P.: A statistical seasonal analysis of winter decreases in ozone at Macquarie Island, Geophys. Res. Lett., 21, 381-384, 1994.

Logan, J. A.: Tropospheric Ozone: Seasonal behavior, trends, and anthropogenic influence, J. Geophys. Res., 90, 10,463-10,482, 1985.

London, J. and Kelley, J.: Global trends in total atmospheric ozone, Science, 184, 987-989, 1974.

Low, P. S., Kelly, P. M., and Davies, T. D.: Variations in surface ozone trends over Europe, Geophys. Res. Lett., 19, 1117-1120, 1992.

Marenco, A., Gouget, H., Nedelec, P., Pages, J. P., and Karcher, F.: Evidence of a long-term increase in tropospheric ozone from Pic du Midi data series: Consequences: Positive radiative forcing, J. Geophys. Res., 99, 16617-16 632, 1994.

Mickley, L. J., Jacob, D. J., and Rind, D.: Uncertainty in preindustrial abundance of tropospheric ozone: Implications for radiative forcing calculations, J. Geophys. Res., 106, 3389-3399, 2001.

Oltmans, S. J., Vomel, H., Hofmann, D. J., Rosenlof, K. H., and Kley, D.: The increase in stratospheric water vapor from balloonborne, frostpoint hygrometer measurements at Washington, D. C., and Boulder, Colorado, Geophys. Res. Lett., 27, 34533456, 2000.

Parry, H. D.: Ozone depletion by chlorofluoromethanes? Yet another look, J. Appl. Meteor., 16, 1137-1148, 1977.

Pavelin, E. G., Johnson, C. E., Rughooputh, S., and Toumi, R.: Evaluation of preindustrial surface ozone measurements made using the Schönbein method, Atmos. Environ., 33, 919-929, 1999.

Rind, D., Shindell, D. T., Lonergan, P., and Balachandran, N. K.: Climate Change and the Middle Atmosphere. Part III: The Dou- bled $\mathrm{CO}_{2}$ Climate Revisited, J. Climate, 11, 876-894, 1998.

Rodgers, C.: Global ozone trends reassessed, Nature, 332, 201201, 1988.

Rosenfeld, D.: Supression of rain and snow by urban and industrial air pollution, Science, 287, 1793-1796, 2000.

Rosenlof, K. H., Oltmans, S. J., Kley, D., et al.: Stratospheric water vapor increases over the past half-century, Geophys. Res. Lett., 28, 1195-1198, 2001

Sander, S. P., Friedl, R. R., DeMore, W. B., et al.: Chemical kinetics and photochemical data for use in stratospheric modeling, Eval. 13, JPL Publ. 00-003, 2000.

Sandroni, S. and Anfossi, D.: Historical data of surface ozone at tropical latitudes, Sci. Total Environ., 148, 23-29, 1994.

Sato, M., Hansen, J. E., McCormick, M. P., and Pollack, J. B., Stratospheric aerosol optical depth, 1850-1990, J. Geophys. Res., 98, 22987-22994, 1993.

Shindell, D. T., Rind, D., and Lonergan, P.: Climate Change and the Middle Atmosphere. Part IV: Ozone Photochemical response to doubled $\mathrm{CO}_{2}$, J. Climate, 11, 895-918, 1998.

Shindell, D. T.: Climate and ozone response to increased stratospheric water vapor, Geophys. Res. Lett., 28, 1551-1554, 2001.

Shindell, D. T., Grenfell, J. L., Rind, D., Price, C., and Grewe, V.: Chemistry climate interactions in the GISS GCM. Part 1: Tropospheric chemistry model description and evaluation, J. Geophys. Res., 106, 8047-8076, 2001.

Staehelin, J., Thudium, J., Buhler, R., Volz-Thomas, A., and Graber, W.: Trends in surface ozone concentrations at Arosa (Switzerland), Atmos. Environ., 28, 75-87, 1994.

Staehelin, J., Kegel, R., and Harris, N. R. P.: Trend analysis of the homogenized total ozone series at Arosa (Switzerland), 19261996, J. Geophys. Res., 103, 8389-8399, 1998.

Staehelin, J., Harris, N. R. P., Appenzeller, C., and Eberhard, J.: Ozone trends: A review, Rev. Geophys., 39, 231-290, 2001.

van Aardenne, J. A., Dentener, F. J., Olivier, J. G. J., Klein Goldewijk, C. G. M., and Lelieveld, J.: A $1^{\circ} \times 1^{\circ}$ resolution data set of historical anthropogenic trace gas emissions for the period 1890-1990, Global Biogeochem. Cycles, 15, 909-928, 2001.

Volz, A. and Kley, D.: Evaluation of the Montsouris series of ozone measurements made in the nineteenth century, Nature, 332, 240 242, 1988.

World Meteorological Organization: Scientific assessment of ozone depletion: 1994, Rep. 37, Geneva, 1995.

World Meteorological Organization: Scientific assessment of ozone depletion: 1998, Rep. 44,Geneva, 1999.

Zhou, X-L., Geller, M. A., and Zhang, M.: Cooling trend of the tropical cold point tropopause temperature and its implications, J. Geophys. Res., 106, 1511-1522, 2001. 